Casos Clínicos

Arch. Esp. Urol., 61, 3 (424-427), 2008

\section{CARCINOMA DE LOS DUCTOS DE BELLINI: APORTACIÓN DE DOS NUEVOS CASOS}

Pedro Carrión López, José Miguel Giménez Bachs, María José Donate Moreno, Héctor Pastor Navarro, Luis Cañamares Pabolaza, Miguel Segura Martín, Manuel Atienzar Tobarra', Antonio Salinas Sánchez y Julio Antonio Virseda Rodríguez.

Servicio de Urología y Anatomía Patológica'. Complejo Hospitalario de Albacete. Albacete. España.

Resumen.- OBJETIVO: Presentamos dos casos de carcinoma de ductos de Bellini diagnosticados en nuestro servicio en un plazo de seis meses.

MÉTODO/RESULTADO: El caso nº 1 es una mujer de 75 años de edad en la que un TAC, realizado por estudio de patología digestiva, mostró una masa en el riñón izquierdo que infiltraba grasa perirrenal. El caso n² es un varón de 72 años que al realizar estudio por TVP bilateral de miembros inferiores, se evidenció en el TAC una lesión renal derecha dependiente de la pelvis, mal definida, con afectación de la vena cava y renal derecha. Tras la realización de nefrectomía radical en ambos casos, se confirmó el diagnóstico anatomopatológico de carcinoma de ductos de Bellini.
CONCLUSIÓN: El carcinoma de los ductos de Bellini es una rara variedad de tumor renal que deriva de los ductos colectores de la médula renal. Caracterizado tanto por su agresividad, como por su peculiar diagnóstico, histológico e inmunohistoquímico, que lo diferencia del resto.

Palabras clave: Carcinoma de los ductos colectores. Tumor renal. Inmunohistoquímica.

Summary.- OBJECTIVE: We report two cases of collecting duct carcinoma that were diagnosed in our hospital in a six-month period.

METHODS/RESULTS: The first case was a 75-years-old woman showing in CT scan a mass in the left kidney which infiltrated perinephric fat. The second case was a 72-yearsold that showed in a CT scan a right renal pelvis lesion, involving inferior vena cava and renal vein. After surgical resection by radical nephrectomy in both cases, we confirmed the histolo-gical diagnosis of collecting duct carcinoma.

CONCLUSIONS: Collecting duct carcinoma is a rare variant of renal cell carcinoma which originates from the epithelium of the collecting tubule. It is characterized by both its aggressiveness and peculiar histological and inmu-nohistochemical diagnosis, that separates it from the rest of renal tumors.

Keywords: Collecting duct carcinoma. Renal tumor. Inmunohistochemic.

\section{INTRODUCCIÓN}

En España se calcula que se diagnostican entre 1500 - 2000 nuevos casos de Carcinoma de Células Renales (CCR) por año, con una incidencia de alrededor de 4 casos por cada 100.000 habitantes (1).

Dentro de la clasificación histológica de Carcinoma de Células Renales (CCR), encontramos el llamado carcinoma de ductos colectores (de Bellini), representando menos de un $1 \%$ de los tumores renales (2). Este tumor presenta un diagnóstico histológico e inmunohistoquímico peculiar, caracterizado por la expresión de citoqueratinas de alto peso molecular.

Presentamos dos nuevos casos de carcinoma de ductos colectores en una mujer y un varón, ambos de edad avanzada.

\section{CASO CLÍNICO nº 1}

Mujer de 75 años de edad con antecedentes de HTA, síndrome depresivo y estreñimiento crónico. Sin antecedentes urológicos de interés. 


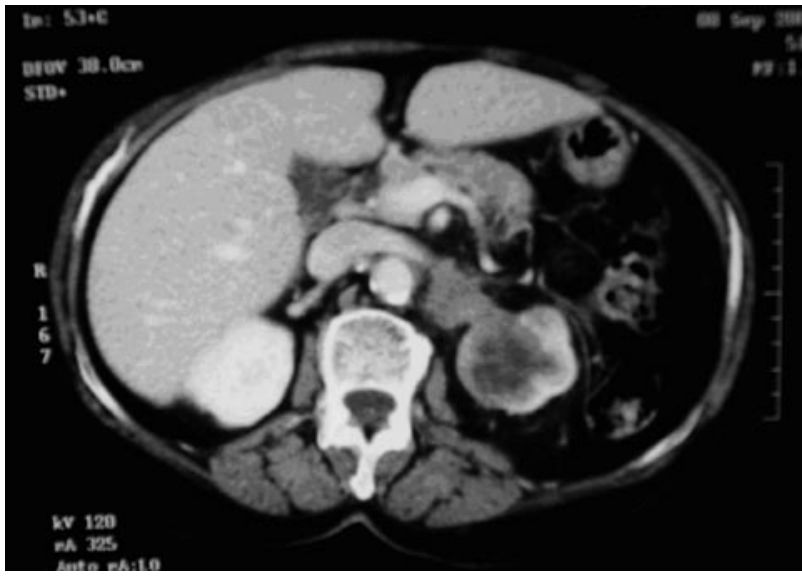

FIGURA 1. Masa renal izquierda con afectación de la vena renal izquierda.

Remitida del Servicio de Digestivo, aportando un TAC abdomino-pélvico, realizado durante un estudio de su patología de base, donde se observaba una masa de aspecto sólido en polo superior del riñón izquierdo de 4,9 $\times 3,6 \mathrm{~cm}$ que infiltraba la grasa perirrenal, con presencia de dos adenopatías en el hilio renal de $1,5 \mathrm{~cm}$. Posible afectación de la vena renal izquierda (Figura 1).

En el estudio de UIV, el riñón derecho era normal; mientras el riñón izquierdo mostraba una anulación funcional, apreciándose al cabo de 2 horas un discreto nefrograma, sin llegar a visualizarse en ningún momento el polo superoexterno del mismo.

En la Angio-RM, se apreciaba una tumoración de 4 $\mathrm{cm}$ que afectaba a $1 / 3$ medio y polo superior de riñón izquierdo, con metástasis en glándula suprarrenal ipsilateral, adenopatías locorregionales y trombosis de la vena renal izquierda, sin afectación de la vena cava (Figura 2).

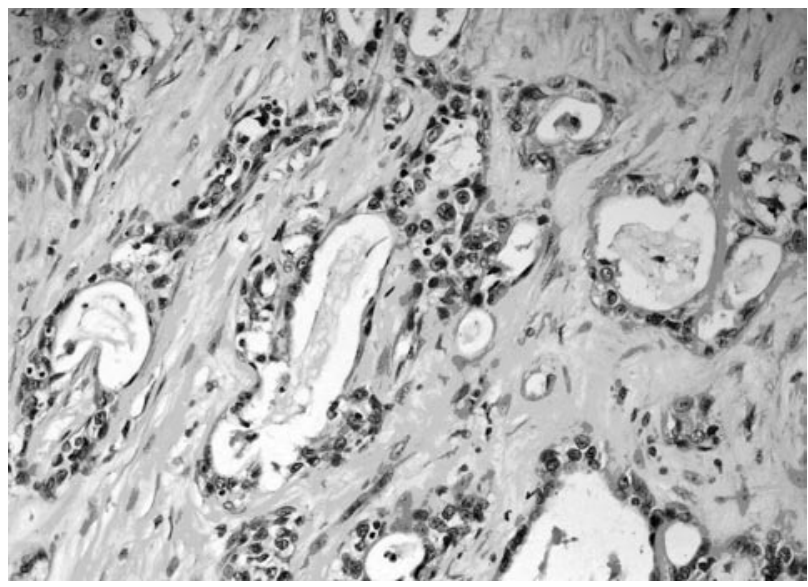

FIGURA 3. Hematoxilina 20x: Tumoración formada por estructuras ductales atípicas

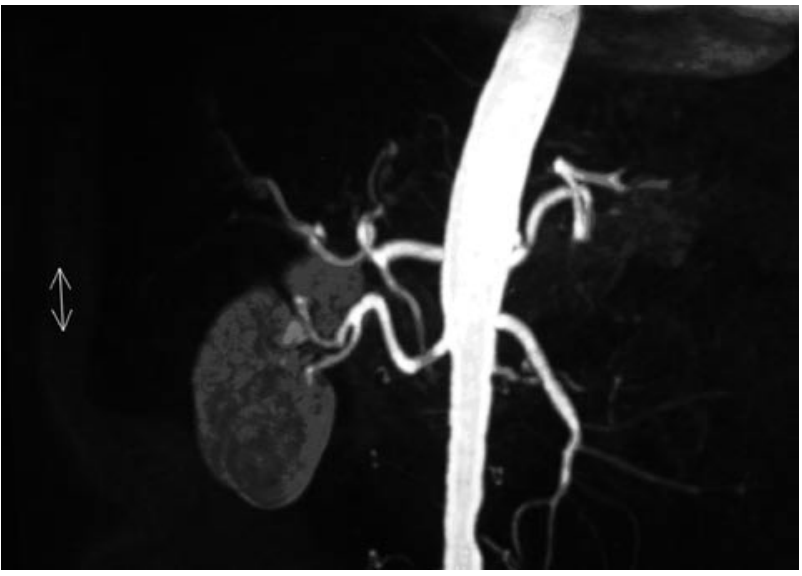

FIGURA 2. Trombosis de la venal renal izquierda.

Ante la sospecha diagnóstica de carcinoma renal, se practicó nefrectomía radical izquierda mediante lumbotomía, apreciando la presencia de un bloque adenopático a nivel del hilio renal.

La descripción macroscópica del estudio anatomopatológico, destacó una pieza de nefrectomía de $10 \times 6$ $\times 7 \mathrm{~cm}$, que su mayor parte se perdía la delimitación córtico -medular, apreciándose masas grisáceas de consistencia firme que sustituían de forma difusa e irregular gran parte del parénquima renal. Por otro lado, la descripción microscópica, apreció una neoplasia maligna formada por estructuras tubulares y ductales atípicas que infiltraba la grasa perirrenal a nivel de la zona del seno renal y alcanzando el borde quirúrgico. Estas estructuras mostraron positividad inmunohistoquímica para keratinas: CAM 5.2; AE 1 - AE2 y 34 BE 12. Estableciendo, de esta manera, el diagnóstico definitivo de carcinoma de ductos colectores con afectación del seno renal del borde quirúrgico (Figuras 3 y 4 ).

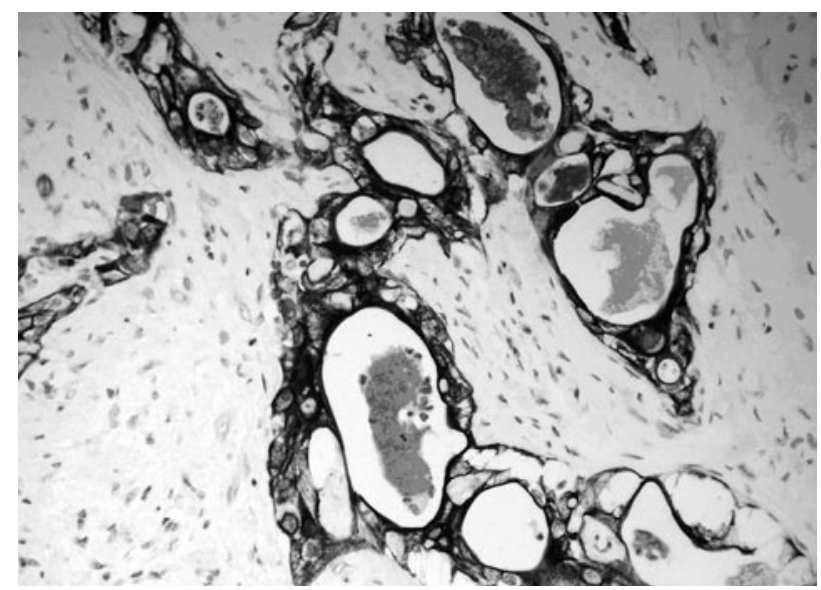

FIGURA 4. Positividad marcada para queratina 34BE 12 
Tras un mes y medio de la cirugía, una vez valorada por el Servicio de Oncología, se decidió comenzar tratamiento quimioterápico con Carboplatino AUC 4 día $1^{\circ}+$ Gencitabina $1250 \mathrm{mg} / \mathrm{m}^{2}$ días $1^{\circ}$ y $8^{\circ}$ cada 21 días. No se administró cisplatino debido a su nefrotoxicidad y a tratarse de una paciente monorrena con un $\mathrm{ClCr}<30$.

Tras el $4^{\circ}$ ciclo de QMT se realizó un TAC en el que se apreció: lesión tumoral en fosa renal izquierda, que infiltraba arteria mesentérica superior, músculo psoas izquierdo y probablemente también aorta, acompañada de una lesión hepática en segmento 4 compatible con metástasis.

\section{CASO CLÍNICO nำ 2}

Varón de 72 años de edad fumador de 60 cigarrillos/ día, con antecedentes de hiperreactividad bronquial, artrosis lumbar cervical.

Tras estudio de tumefacción y dolor en ambas extremidades inferiores, se realizó Ecodoppler de miembros inferiores informando de trombosis venosa profunda bilateral.

En el estudio de TC abdómino - pélvico, se objetivó una lesión renal derecha heterogénea que parecía depender de la pelvis (Figura 5), mal definida, con afectación de la vena cava, vena renal y músculo psoas derecho, así como trabeculación de la grasa adyacente. Fase excretora enlentecida. Trombo en cava inferior y ambas ilíacas. Adenopatías retroperitoneales menores de $1 \mathrm{~cm}$.

Se realizó angio - RM abdominal que informó como: hipoplasia del segmento intrahepático de la vena cava in-

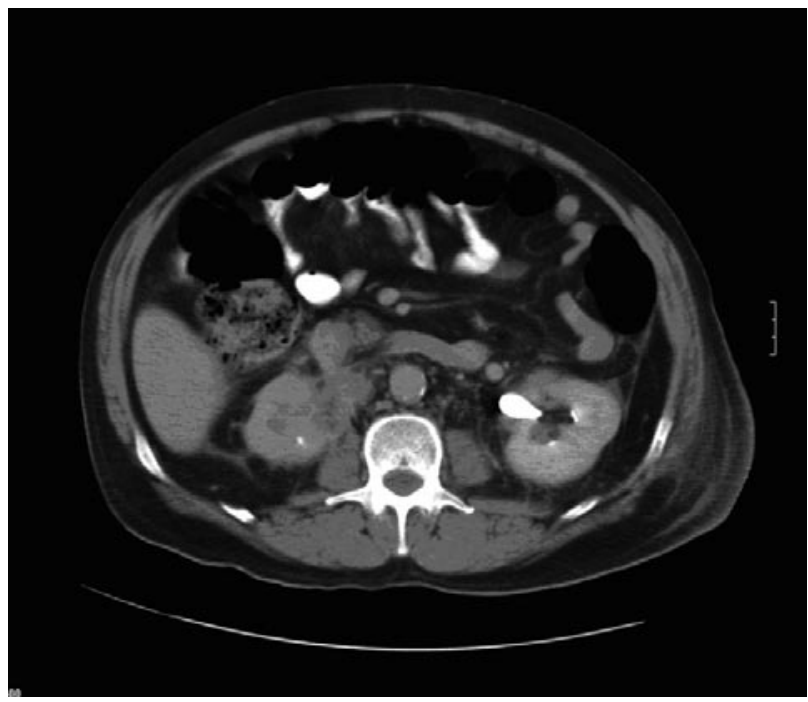

FIGURA 5. Tumoración de la pelvis renal derecha. ferior con importante circulación colateral a través de la ácigos y hemiácigos. Tumoración renal derecha que se extendía a partes blandas con adenopatías retrocavas que desplazaban a la vena cava inferior hacia adelante comprimiéndola y dejándola de un calibre filiforme.

Ante la sospecha diagnóstica de carcinoma renal, mediante laparotomía subcostal transperitoneal derecha en la que se apreció un gran fumor renal derecho que invadía estructuras adyacentes lángulo derecho del colon, $3^{\circ}$ porción duodenal, y estructuras vasculares retroperitoneales: vena cava y aorta abdominal), se decidió realizar una nefrectomía radical derecha acompañada de linfadenectomía regional de bloque adenopático, junto con liberación de vena cava y extirpación de parche de $3^{\circ}$ porción duodenal.

La descripción macroscópica del estudio anatomopatológico, destacó una pieza de nefrectomía de $8 \times 5 \mathrm{~cm}$, apreciándose tumoración difusa grisácea de consistencia firme que mide $5 \mathrm{~cm}$ de diámetro máximo y se extiende a grasa perirrenal. Por otro lado, la descripción microscópica, apreció una neoplasia maligna formada por células epiteliales y estructuras ductales. Estas estructuras mostraron fuerte positividad para queratina 34 $B E 12$. Invadía la pared de la vena renal, alcanzando el borde quirúrgico. Metástasis en dos ganglios linfáticos. De esta manera, se estableció el diagnóstico definitivo de carcinoma de ductos colectores con afectación del borde quirúrgico, de la vena renal y diseminación linfática.

El paciente falleció, por fallo multiorgánico, al tercer día de postoperatorio.

\section{DISCUSIÓN}

El carcinoma de ductos colectores representa menos de $1 \%$ de los casos de cáncer de células renales. Con una prevalencia 2:1 en relación hombres y mujeres y una edad media de aparición de 66 años (2).

Clínicamente se manifiesta de manera similar al carcinoma renal de células claras, por lo que resulta difícil pensar en esta patología como un diagnóstico inicial.

Radiológicamente, al tratarse de un tumor de origen medular, tiende a preservar la morfología renal externa (3). No obstante, resultará complicado distinguir cual es el origen real del tumor apreciado en la prueba de imagen, debido a su rápido crecimiento y a la temprana invasión de tejidos periféricos, como en los casos que presentamos.

Entre sus peculiaridades destaca su agresividad, presentándose hasta el $50 \%$ de los casos con metástasis al diagnóstico, y con una tasa de mortalidad próxima al $100 \%$ a los 3 años (4). 
Genéticamente no se aprecian alteraciones el cromosoma 3 ni en el 7 (5). Sin embargo, se han descrito monosomías en los cromosomas 1, 6, 14, 15 y $22(6,3)$.

Macroscópicamente se define como una lesión sólida grisácea difusa e irregular que, aunque en determinadas ocasiones preserva el contorno renal, habitualmente deforman las papilas protuyendo en la pelvis renal (7).

Microscópicamente se describe como un tumor tubular o tubulopapilar con un estroma con marcada desmoplasia, con infiltrado inflamatorio de predominio polimorfonuclear y alto grado nuclear (2). Son características las células con núcleos irregulares y prominente nucleolo con aspecto típico "en tachuela" (3).

Inmunohistoquímicamente pueden mostrar positividad para el antígeno de epitelio de membrana (EMA), citoqueratinas $A E 1$ y $C A M$ 5.2, vimentina, (SBA), (PNA), (DBA), y a diferencia de los tumores originados en el túbulo proximal, suelen mostrar negatividad para LeuM1(8 y 9). En nuestros dos casos se mostró positividad $34 \mathrm{BE} 12$, mientras que en el primer caso, también lo fue para keratinas: CAM 5.2; AE 1 - AE2. Este patrón inmunohistoquímico es más similar al carcinoma transicional de pelvis renal que al carcinoma de células renales (10).

La OMS ha definido criterios mayores y menores para establecer el diagnóstico: Criterios mayores: Histología típica con arquitectura irregular tubular y alto grado nuclear, estroma desmoplásico con infiltrado inflamatorio, ausencia de carcinoma urotelial y reactividad a Ulex Europaeus. Criterios menores: arquitectura papilar con signos de desmoplasia, atipia epitelial intratubular en ductos adyacentes al tumor (1 1 y 12$)$.

\section{CONCLUSIÓN}

El tratamiento inicial debe ser quirúrgico mediante nefrectomía radical ampliada (13). Sin embargo, todavía no hay consenso respecto al tratamiento adyuvante, puesto que tanto los intentos de inmunoterapia como de quimioterapia han mostrado poca respuesta (8), debido en parte, a la escasez de pacientes con este tipo de tumor que dificulta el estudio del mismo. No obstante, hay publicaciones $(14,4,15,16)$ en la que se han sugerido tratamientos adyuvantes con quimioterapia e inmunoterapia, basándose en la similitud inmunohistoquímica con el carcinoma transicional de pelvis renal, pero los resultados, hasta la fecha, no son concluyentes. En nuestro primer caso, decidimos administrar tratamiento quimioterápico mediante Carboplatino + Gencitabina debido a la situación renal de la paciente (monorrena y $\mathrm{CLCR}<30$ ), pauta que no consiguió la respuesta esperada como se apreció en descripción previamente realizada del TAC de control.

\section{BIBLIOGRAFÍA y LECTURAS RECOMENDADAS (*lectura de interés $y^{* *}$ lectura fundamental)}

1. RESEL, L.E.; RAMÍREZ, F.; MARRERO, R.: "Estadiaje tumoral y factores pronósticos del carcinoma de células renales". Oncología urológica. $1^{\text {a }}$ Edición. Resel Estévez L, Moreno Sierra J. Madrid, España. Edit. Grupo Saned, pág. 337- 356, 2003.

2. MÉJEAN, A.; ROUPR, T.M.; LAROUSSERIE, F. y cols.: "Is there a place for radical nephrectomy in the presence of metastatic collecting duct (Bellini) carcinoma?". J. Urol., 169: 1287, 2003.

3. DE PABLO, A.; PINOS, M.A.; JIMÉNEZ, J.I. y cols.: "Carcinoma de ductos colectores de Bellini". Arch. Esp. Urol., 57: 153, 2004.

4. DE DIEGO, E.; PASCUAL, C.; GUTIERREZ, J.L. y cols.: "Carcinoma de Bellini. Nuestra experiencia". Arch. Esp. Urol., 53: 611, 2000.

*5. DE DIEGO, E.; HERNANDEZ, R.; MARTIN, B. y cols.: "Masa retroperitoneal secundaria a carcinoma de Bellini”. Actas Urol. Esp., 23: 801, 1999.

*6. MARTÍNEZ BARBA, E.; LÓPEZ CUBILLANA, P.; SOLA PEREZ, J. y cols.: "Bellini duct carcinoma of the kidney". British Journal of Urology, 80: 342, 1997.

**7. ORSOLA, A.; TRIAS, I.; RAVENTÓS, C. y cols.: "Renal collecting (Bellini) duct carcinoma displays similar characteristics to upper tract urothelial cell carcinoma". Urology, 65: 49, 2005.

8. ORTIZ GORRAIZ, M.; ROSALES, J.L.; TALLADA, M. y cols.: "Collecting duct carcinoma of the kidney with retroperitoneal lymph mass". Arch. Esp. Urol., 57: 179, 2004

*9. KOIKAWA, Y.; SAKAMOTO, N.; NAITO, S. y cols.: "Bellini duct carcinoma of the kidney". Eur. Urol., 22: 171, 1992.

10. SAN MIGUEL FRAILE, P.; DOS SANTOS, J.E.; DELGADO, C. y cols.: "Carcinoma renal de los ductos colectores de bajo grado. Presentación de un caso y revisión de la literatura”. Actas Urol. Esp., 28: 478, 2004.

11. ALGABA, F.; ARCE, Y.; TRIAS, I. y cols.: "Aplicación clínica de las actuales clasificaciones del cáncer renal". Actas Urol. Esp., 30: 372, 2006.

12. SRIGLEY, J.R.; MOCH, H.: "Carcinoma of the collecting ducts of Bellini”. Eble, J.N.; Sauter, G.; Epstein, J.I.; Sesterhenn, I.A. World Health Organization Classification of tumours. Pathology and Genetics Tumours of the urinary system and male genital organs. Lyon, pág. 33-34, IARC Press, 2004.

*13. MONSERRAT, V.; LÓPEZ, E.; PÉREZ, F. y cols.: "Carcinoma de ductos de Bellini: A propósito de un caso". Arch. Esp. Urol., 50: 798, 1997.

*14. KIRKALI, Z.; CELEBI, I.; AKAN, G. y cols.: "Bellini duct (collecting duct) carcinoma of the kidney". Urology, 47: 921, 1996.

15. CARTER, M.D.; THA, S.; McLOUUGLIN, M.G. y cols.: "Collecting duct carcinoma of the kidney: A case report and review of the literature". J. Urol., 147: 1096, 1992.

*16. MILOWSKY, M.I.; ROSMARIN, A.; TICKOO, S.K. y cols.: "Active chemotherapy for collecting duct carcinoma of the kidney. A case report and review of the literature". Cancer, 94: 111, 2002. 